\title{
JOURNAL.RU
}

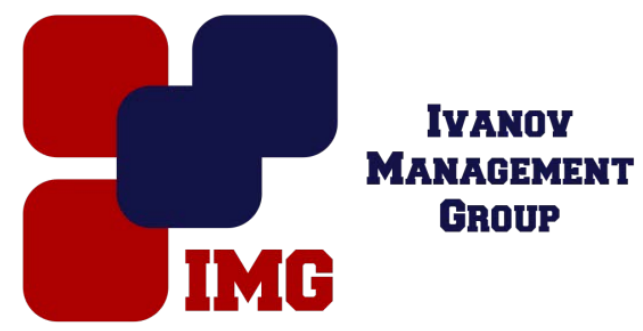

Девликанова С.С. Национальный исследовательский университет «МИЭТ» Москва, Россия

doi: 10.18411/lj-31-01-2017-4-03

idsp 000001:lj-31-01-2017-4-03

\section{Моделирование КНИ полевого датчика Холла}

\section{Аннотация}

Разработана математическая модель маршрут моделирования КНИ ПДХ в системе TCAD. Проведено исследование выходных и передаточных характеристики КНИ ПДХ, которые имеют хорошее совпадение с экспериментальными характеристиками. Полученные результаты подтверждают физическую модель КНИ ПДХ и особенности работы прибора в области неполного обеднения, при котором образуется проводящий канал в теле КНИ ПДХ. Разработанная математическая модель позволяет более детально изучать особенности функционирования КНИ полевого датчика Холла..

Ключевые слова: КНИ полевой датчик Холла, повышенная магниточувствительность, режим неполного обеднения и обогащения, ВАХ, зарядовое состояние, математическое моделирование.

\section{Abstract}

In the paper we have studied a mathematical model and The TCAD simulation route of the SOI field-effect Hall sensor. The results confirm the physical model of the SOI field-effect Hall sensor and features of the device inpartical depletion, where the conducting channel is formed in the body of the SOI field-effect Hall sensor. The development mathematical model allows us to study the features of the SOI fieldeffect Hall sensor operation in details.

Keywords: SOI field-effect Hall sensor, increased magnetics sensitivity, the partically depletion mode and the saturation, CVC, charge state, mathematical model.

Полевые датчики Холла на основе КНИ структуры (КНИ ПДХ) облагают рядом преимуществ, обусловленных использованием системы «кремний-наизоляторе» и наличием двух управляющих электродов [1-3]. Анализ научнотехнической литературы показал, что публикации,посвященные математическому моделированию КНИ ПДХ практически отсутствуют. 
Ввиду того, что ПДХ имеет крестовидную топологию, расчет электрических вольтамперных характеристик, в том числе получения Холловской ЭДС в магнитном поле, возможны только при использовании математического моделирования трехмерной структуры. Однако для исследования ВАX прибора и распределения электронов, электрического поля в теле КНИ ПДХ достаточно настроить двумерную модель датчика в Synopsys TCAD.

Для численного расчета в Synopsys TCAD на начальном этапе проводилась разработка и настройка математической модели путём сопоставления передаточной характеристики, описанной в работе [2] и рассчитанной с помощью TCAD [4]. Была разработана двумерная математическая модель в соответствии с сечением ПДХ на рисунке 1.

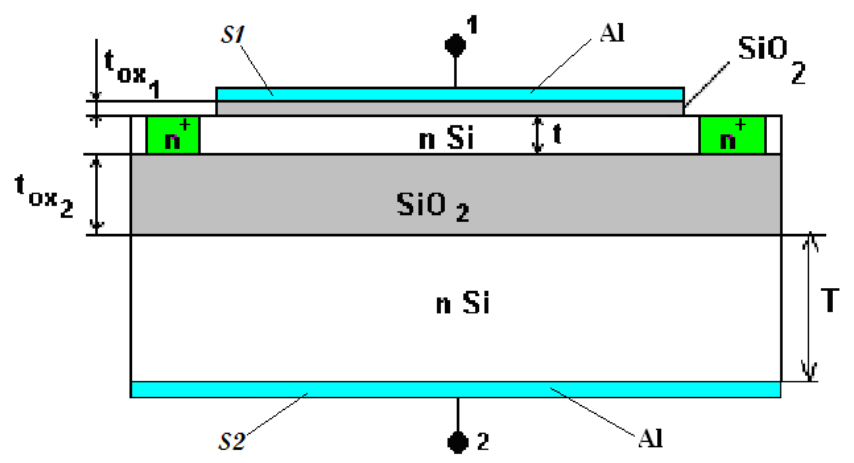

Рисунок 1. Поперечное сечение КНИ ПДХ

1,2 - контакты верхнего и нижнего затворов, $\mathrm{t}$ - толщина рабочего слоя кремния, tox1 -толщина верхнего подзатворного диэлектрика,tox2 - толщина скрытого диэлектрика КНИ структуры, Т-толщина подложки.

Структура прибора на основе сечения рис.1 задавалась аналитически в программе Sentaurus SDE, где создавались слои, указывалась концентрация примеси в них, наносились контакты, а также в программе осуществлялось построение расчетной сетки для последующего расчета физики прибора.

Проводилась следующая настройка математической модели. Для расчетов BAX в модуле SDEVICE применялись модели DopingDep и Enormal, учитывающие зависимость подвижности носителей заряда от концентрации примеси и поперечного электрического поля. Параметры указанных моделей использовались по умолчанию и отдельно не уточнялись. Задавался барьер между уровнем Ферми металла, т.е. верхним электродом затвора, и уровнем Ферми кремния, т.е. рабочим слоем, через тонкий подзатворный диэлектрик. Концентрация поверхностных состояний, вызванных поверхностным зарядом на границе $\mathrm{Si} / \mathrm{SiO} 2$, задавалась, равной Nss $=1011$ см-3. С помощью итерационного метода проводилось изменение функции по изменению аргумента. Построение передаточных и выходных ВАХ осуществлялось в модуле INSPECT.

Сравнение экспериментальной и расчетной передаточных характеристик, представленное ранее в нашей работе [4], имеют хорошее совпадение, что 
свидетельствует об адекватности разработанной математической модели реальному образцу прибора.

Расчет выходной и передаточной ВАХ КНИ ПДХ проводился при отсутствии внешнего магнитного поля на основе решения уравнений непрерывности для электронов и дырок, а также уравнения Пуассона в рамках диффузионно-дрейфовой модели. Семейство рассчитанных выходных и передаточных характеристик при разных напряжениях затвор-исток и стокистокприведены на рис. 2 и на рис. 3 соответственно.

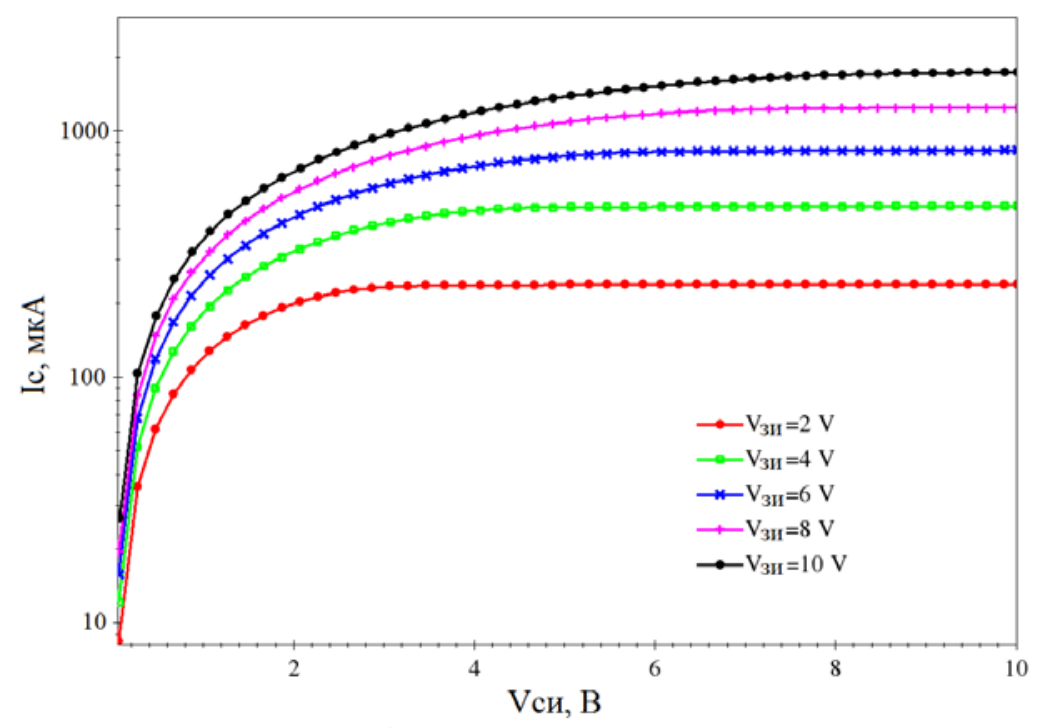

Рисунок 2. Семейство рассчитанных выходных характеристик КНИ ПДХ в зависимости от напряжения затвор-исток.

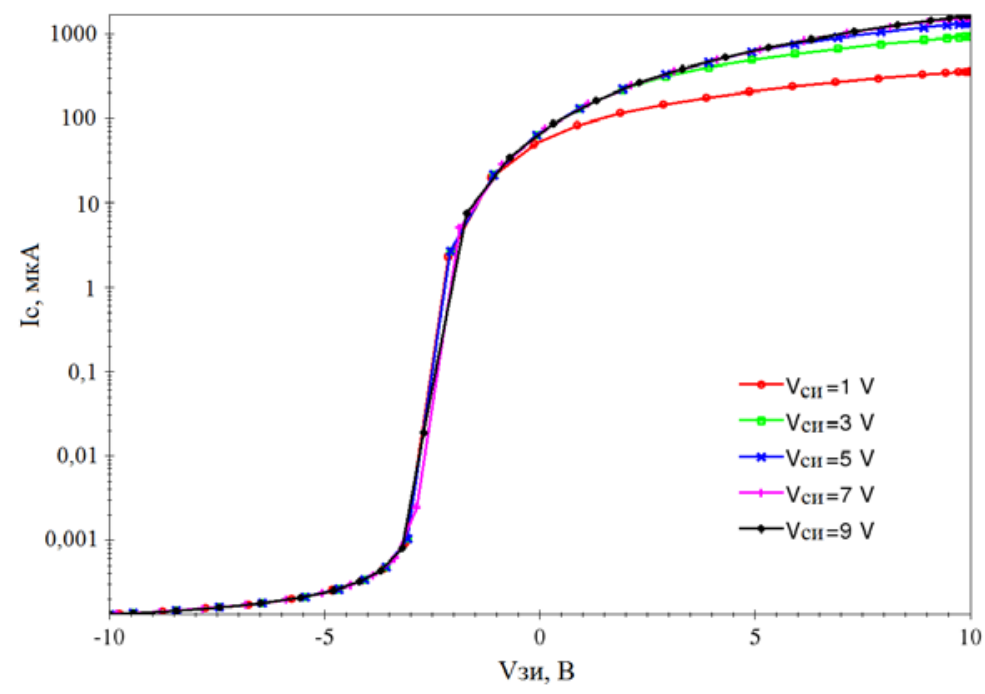

Рисунок 3. Семейство передаточных ВАХ КНИ ПДХ при различном напряжении сток-исток

Таким образом, разработанмаршрут моделирования КНИ ПДХ в системе TCAD. C использованием разработанной методики математического моделирования построены выходные и передаточные характеристики КНИ ПДХ. 


\section{Литература}

1. Baranochnikov M. L., Leonov A. V., Mordkovich V. N., Pazhin D. M. Filatov M. M. Some Features of Magnetometric and Sensor Devices Based on the Field Effect Hall Sensor //Advanced Electromagnetics Symposium. Proceedings. - Paris, France, 2012- P.455-459.

2. МордковичВ.Н., БараночниковМ.Л., ЛеоновА.В, МокрушинА.Д., ОмельяновскаяН.М., ПажинД.М. Полевойдатчикхолла - новыйтиппреобразователямагнитногополя // Датчикиисистемы. - 2003- Вып. 7. - С.33-38.

3. Королёв М.А., Козлов А.В., Петрунина С.С. Особенности функционирования полевого датчика Холла на основе КНИ структур, предназначенного для работы в телекоммуникационных сетях // Труды МФТИ. - 2015. - Том7, №3 - С. 91-95

4. Козлов А.В., Королёв М.А., Петрунина С.С. Математическое моделирование влияния концентрации примеси на ток стока КНИ полевого датчика Холла // Известия высших учебных заведений. Электроника. - 2015 - №4 - С. 377-381. 